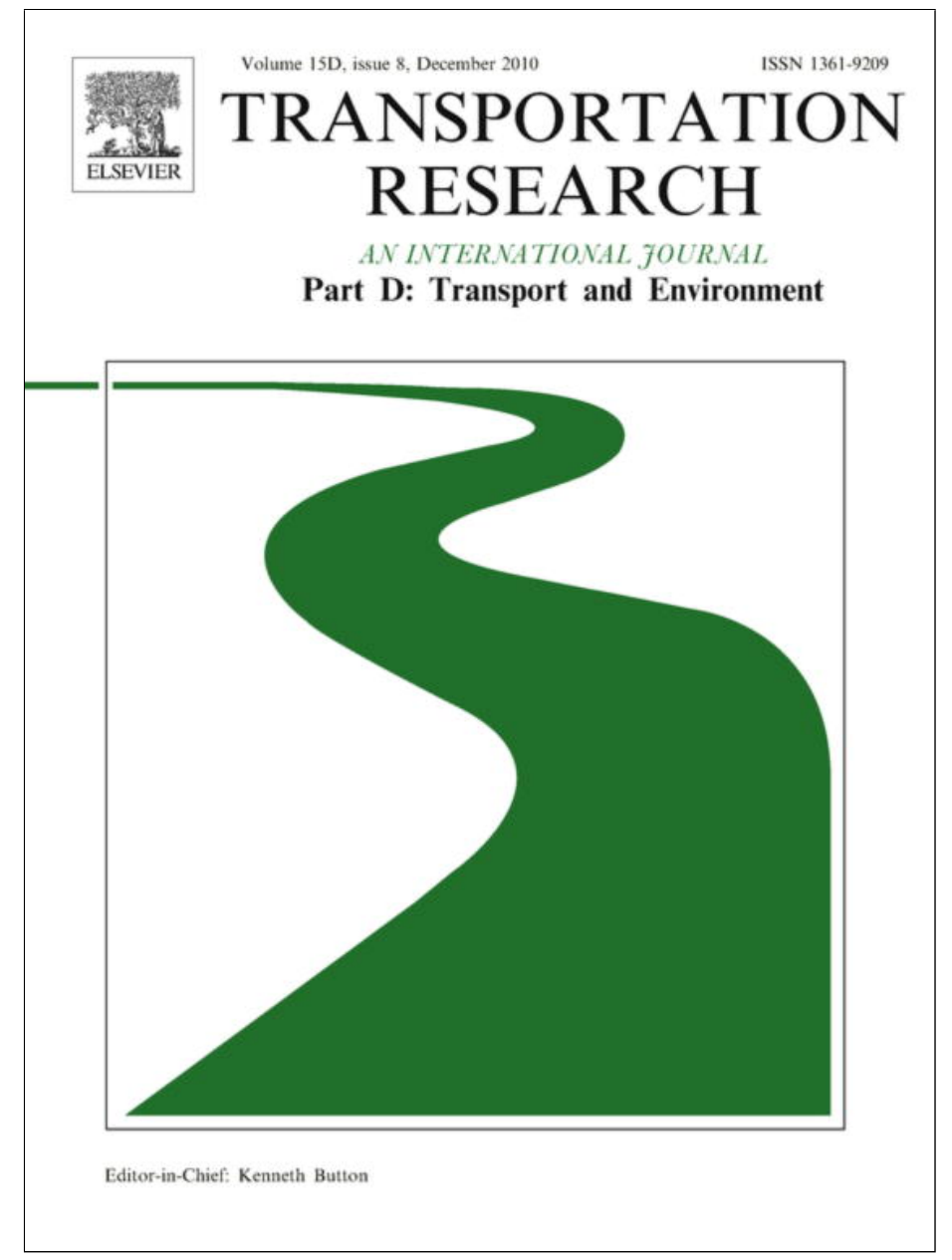

This article appeared in a journal published by Elsevier. The attached copy is furnished to the author for internal non-commercial research and education use, including for instruction at the authors institution and sharing with colleagues.

Other uses, including reproduction and distribution, or selling or licensing copies, or posting to personal, institutional or third party websites are prohibited.

In most cases authors are permitted to post their version of the article (e.g. in Word or Tex form) to their personal website or institutional repository. Authors requiring further information regarding Elsevier's archiving and manuscript policies are encouraged to visit:

http://www.elsevier.com/copyright 


\title{
Using measured instead of perceived noise in hedonic models
}

\author{
Andrea Baranzini ${ }^{\mathrm{a}, *}$, Caroline Schaerer ${ }^{\mathrm{a}}$, Philippe Thalmann ${ }^{\mathrm{b}}$ \\ ${ }^{a}$ Geneva School of Business Administration, Center for Applied Research in Management, University of Applied Sciences of Western Switzerland, \\ 7 Route de Drize, $\mathrm{CH}-1227$ Carouge, Geneva, Switzerland \\ ${ }^{\mathrm{b}}$ EPFL Swiss Institute of Technology Lausanne, Institute of Urban and Regional Sciences, Station 16, 1015 Lausanne, Switzerland
}

\section{A R T I C L E I N F O}

Keywords:

Road traffic noise hedonic model

External cost

Monetary valuation

Geographical information system

\begin{abstract}
A B S T R A C T
This paper compares the use of perceived and measured noise in a hedonic housing model. Although in theory the use of subjective variables is recommended, most empirical applications use measured noise variables. Merging different databases, we obtain a sample of about 2800 apartments located in Geneva, Switzerland, containing both measured and perceived noise data. We make the measured and perceived noise data comparable and analyse their performance by fitting alternatively three hedonic models. We find that for moderate to high noise levels the measured noise safely approximates its perception.
\end{abstract}

(c) 2010 Elsevier Ltd. All rights reserved.

\section{Introduction}

This paper compares the use of perceived and measured noise in hedonic price models (HPM) in housing markets. HPMs estimate implicit prices for housing characteristics from the observed prices of differentiated housing units and the quantities of characteristics associated with them. ${ }^{1}$ Some property characteristics, such as the number of rooms in the dwelling, are variables that are easily observable and thus there is no difference between their measure and households' perception of them. However, other housing characteristics such as "a good view" or "a quiet area" are not directly quantifiable and depend on perceptions, which can vary quite substantially across individuals. As highlighted by Palmquist (2005), if property values are to be affected by an environmental amenity such as noise, it has to be perceived by the residents. In other words, the measure of noise in HPM should be that which influences home buyers or renters when they choose a dwelling.

Although many countries now require cost benefit justifications for implementing public policies or authorizing major infrastructure, and the setting of compensation for noise damage requires valuations, relatively few HPM use perceptionbased data. This is mainly for two reasons. First, collecting perceptions from individuals is time-consuming, costly and sensitive. Secondly, from a policy-making perspective, objective measures are more convenient and transferable than subjective perceptions.

Given that most HPM use objective measures of environmental quality, it is insightful to test whether these are reliable proxies for perceptions. There has been little consideration of the appropriateness of using objective measures, especially in the context of noise. Heuristic empirical comparisons of HPM with stated preference techniques (SP), in which survey data were used to value noise impacts have little consistency patterns regarding valuations. Pommerehne (1987) and Soguel (1994) in comparing results found similar willingness-to-pay (WTP) functions with SP and HPM approaches for road traffic noise reduction. Navrud (2002), however, observed that SP questions used by Pommerehne and Soguel are not well understood by many respondents. Bjørner (2004) used dose-response relationships to transform the WTP to avoid noise annoyance reported in a survey into an "expected-WTP" per decibel. He compared the "expected-WTP" from the SP to the implicit

\footnotetext{
* Corresponding author.

E-mail address: Andrea.Baranzini@hesge.ch (A. Baranzini).

1 Baranzini et al. (2008) surveys the use of HPM and Nelson (2008) reviews the work on transportation noise.
} 
Table 1

Descriptive statistics of the noise variables.

\begin{tabular}{|c|c|c|c|}
\hline \multicolumn{4}{|c|}{ Daytime noise level $\left(L r_{D}\right)$ in $\mathrm{dB}(\mathrm{A})(n=2840)$} \\
\hline Sample mean $=65$ & Freq. & Percent & Cum. \\
\hline $50 \leqslant L r_{D}<55$ & 93 & 3.27 & 3.27 \\
\hline $55 \leqslant L r_{D}<60$ & 551 & 19.40 & 22.68 \\
\hline $60 \leqslant L r_{D}<65$ & 976 & 34.37 & 57.04 \\
\hline $65 \leqslant L r_{D}<70$ & 964 & 33.94 & 90.99 \\
\hline $70 \leqslant L r_{D}$ & 256 & 9.01 & 100.00 \\
\hline \multicolumn{4}{|c|}{ Day-night noise index $\left(L_{d n}\right)$ in $\mathrm{dB}(\mathrm{A})(n=2840)$} \\
\hline Sample mean $=67$ & Freq. & Percent & Cum. \\
\hline $50 \leqslant L_{d n}<55$ & 79 & 2.78 & 2.78 \\
\hline $55 \leqslant L_{d n}<60$ & 496 & 17.46 & 20.25 \\
\hline $60 \leqslant L_{d n}<65$ & 920 & 32.39 & 52.64 \\
\hline $65 \leqslant L_{d n}<70$ & 949 & 33.42 & 86.06 \\
\hline $70 \leqslant L_{d n}$ & 396 & 13.94 & 100.00 \\
\hline \multicolumn{4}{|l|}{ Perceived external noise $(n=2808)$} \\
\hline Sample mean $=2.3$ & Freq. & Percent & Cum. \\
\hline No external noise (rate 0 ) & 75 & 2.67 & 2.67 \\
\hline Little noise (rate 1 ) & 573 & 20.41 & 23.08 \\
\hline Moderate noise (rate 2) & 1018 & 36.25 & 59.33 \\
\hline Important noise (rate 3) & 718 & 25.57 & 84.90 \\
\hline Very important noise (rate 4 ) & 424 & 15.10 & 100.00 \\
\hline
\end{tabular}

Sources: From on Rent Structure 2003, and from the Geneva Cantonal Office for Protection against Noise.

price of noise from a HPM and found that, for some noise abatement scenarios, the negative impact on prices is higher with the HPM than with SP, while for other scenarios results are comparable. The approach, however, only compares the SP and HPM results in two specific cases, i.e. halving and full elimination of the noise level.

\section{Making measured and perceived noise comparable}

\subsection{Measured noise variables}

Bateman et al. (2001) argue that it is difficult to find a measure of noise that truly reflects its impact on individuals because noise annoyance does not only depend on its magnitude, but also of its intensity, frequency, duration, variability and time of occurrence. In addition, traffic noise annoyance depends on the type of vehicles, road surface, other background noise, etc. In practice, starting from measured noise, expressed in A-weighted decibels on a logarithmic scale, $\mathrm{dB}(\mathrm{A})$, different indices have been constructed to account for annoyance. For example, the day-night noise index $\left(L_{d n}\right)$ and the day-eveningnight noise index $\left(L_{d e n}\right)$ used by the European Union add $5 \mathrm{~dB}(\mathrm{~A})$ to evening noise and $10 \mathrm{~dB}(\mathrm{~A})$ to night-time noise. Based on Schultz's (1978) most hedonic studies choose an exponential functional form for the hedonic equation. More generally, the measured noise variables used in HPM studies are expressed on the A-weighted decibel scale, $\mathrm{dB}(\mathrm{A})$, to better approximate the noise perceived by the human ear.

The Geneva Cantonal Office for Protection against Noise calculates annual average day $\left(L r_{D}\right)$ and night-time $\left(L r_{N}\right)$ road traffic noise levels in $\mathrm{dB}(\mathrm{A})$. Noise is measured at some fixed points and then extrapolated for the most exposed façade of the buildings using noise curves and taking into account the distance to the road, reflection factors, hindrances, etc. ${ }^{2}$ Using these data, we calculate the day-night road traffic noise index $\left(L_{d n}\right)$, which better accounts for the higher annoyance of noise during the night:

$$
L_{d n}=10 \log \left[10^{L r_{D} / 10}(15 / 24)+10^{\left(L r_{N}+10\right) / 10}(9 / 24)\right]
$$

The noise levels in the sample are briefly described in Table 1.

The $L r_{D}$ in our sample is $65 \mathrm{~dB}(\mathrm{~A})$, a value slightly smaller than the $L_{d n}$. Only about $3 \%$ of the apartments are exposed to a noise level lower than the $55 \mathrm{~dB}(\mathrm{~A})$ that correspond to the planning regulation for residential areas in Swiss law. Similarly, only about $23 \%$ of the dwellings are exposed to a noise level that is below the legal limit of $60 \mathrm{~dB}(\mathrm{~A})$ and about $9 \%$ are exposed to a noise level that equals or exceeds the alert limit of $70 \mathrm{~dB}(\mathrm{~A})$. Very similar results are obtained for the day-night noise index. These values refer to the noise exposure of the building itself and do not account for potential phonic insulation, such as double-glazed windows, which can substantially reduce the noise exposure inside the dwelling. Moreover, for

\footnotetext{
${ }^{2}$ Swiss noise regulations stipulates that the yearly averaged road traffic noise in residential areas should not exceed $60 \mathrm{~dB}(\mathrm{~A})$ during the day and $50 \mathrm{~dB}(\mathrm{~A})$ during the night (Swiss Noise Abatement Ordinance 1986).
} 
policy-making reasons, noise is often measured where the road traffic noise is suspected to be high, which implies that the average noise level in our sample may overestimate the effective average noise exposure in the Canton of Geneva.

\subsection{Perception of noise}

To compare measured and perceived noise, we need data in comparable units. A perceived noise assessment that would be directly comparable to our measured variables would result from a survey question such as: "To what decibel level of road traffic noise do you feel your dwelling is exposed?" Classes of decibels or pure decibel levels could be proposed as multiplechoices answers to help the respondents. Unfortunately, such a survey is not available. However, we have access to the 2003 Statistical information survey on rents of the Swiss Federal Statistical Office, in which the respondents answered a qualitative question on the perceived level of external noise. The question was the following: "How important do you rate the noise coming from outside the building into your dwelling? 0 = no noise; 1 = small; 2 = moderate; 3 =important; 4 = very important noise". Table 1 shows that in our sample the mean perceived external noise is 2.3 , a value that is slightly above the "moderate external noise" category (2). ${ }^{3}$

The perceived noise variable is obviously not directly comparable to the measured yearly averaged daytime traffic noise (in $\mathrm{dB}(\mathrm{A})$ ). The polyserial correlation between these two variables is only $33 \%$. This result can be explained by different factors. Firstly, different persons may perceive and assess the same level of noise quite differently. For example, a given noise level may be more annoying for older people than younger ones. Secondly, low correlation might result because perceived noise refers to all external noises, while measured noise refers to the road traffic noise only. Therefore, an apartment near the airport but away from busy roads might be assessed as very noisy while the actual road traffic noise is low. Finally, a weak relationship might be due to the fact that measured noise is taken outside the dwelling, while respondents were asked about the incidence of external noise inside their dwelling. This latter can be affected by insulation, such as double-glazed windows. A multinomial logit model estimation indeed confirms that perceived noise increases with the age of the building and its lack of renovation. If the building is recent or recently renovated, the probability that the "no noise" category is chosen is higher than the probability to choose any other category.

While it is difficult to compare perceived with measured noise, previous work in acoustics allows us to transform categorical perceived noise data into a variable that is comparable to the measured noise in decibels.

\subsection{Transformation of the perceived noise variable}

Miedema and Vos (1998) and Miedema and Oudshoorn (2001) drew exposure-response functions showing how noise annoyance is associated with a given noise exposure level, for different transportation noise sources. More specifically, they performed a meta-analysis using 55 datasets for 63,969 respondents and fitted a model in which the percentage of highly annoyed people (\%HA) is a function of the day-night noise level $\left(L_{d n}\right)$ and an error term representing the variability of the annoyance reactions by noise exposure level. For road traffic noise, the relationship between annoyance and noise level is ${ }^{4}$ :

$$
\% \mathrm{HA}=0.03\left(L_{d n}-42\right)+0.0353\left(L_{d n}-42\right)^{2}
$$

A simple use of this relationship would be to take the measured noise, $L_{d n}$, to get the percentage of highly annoyed people (\%HA). Alternatively, it can be inverted to transform the \%HA into an equivalent measure of perceived noise expressed in $\mathrm{dB}(\mathrm{A})$, which we call "subjective $L_{d n}$ " and which can be compared to measured day-night noise. We follow this second route, which involves (i) on a 0-4 scale of the categorical variable, determine the cut-off point of people highly annoyed by external noise; (ii) use the cut-off point to calculate the percentage of highly annoyed individuals in the sample; (iii) transform this percentage into subjective $L_{d n}$ by using the reverse of the polynomial function 2 .

To find the cut-off point of highly annoyed people on the $0-4$ scale we use Miedema and Oudshoorn who found that 72 on a 0-100 scale represents the cut-off point defining highly annoyed individuals (\%HA). This corresponds to a cut-off point of 2.88 on our scale; hence respondents indicating a level of perceived noise of 3 and 4 are counted as highly annoyed by external noise. Category 2, with 2 as lower bound and 3 as higher bound, requires more attention since it encompasses the cut-off point. The value assigned to these respondents is the probability that these individuals belong to the highly annoyed group, assuming that the annoyance score is uniformly distributed within the category. On this basis, $12 \%$ of the respondents who chose category 2 are treated as highly annoyed. ${ }^{5}$

The shares of responses in the sample that exceed the cut-off point for $3 \mathrm{~dB}(\mathrm{~A})$ intervals of measured $L_{d n}$ are calculated (Fig. 1). As expected, the percentage of highly annoyed people increases with the day-night noise level, but the correlation is not perfect; respondents who feel highly exposed at low measured road noise levels might suffer from other noise sources, such as aircrafts, railways, children or bars. Conversely, respondents who declared themselves little exposed to noise in spite of high measured noise levels might be less sensitive or protected by efficient acoustic insulation.

\footnotetext{
${ }^{3}$ A probit model was estimated to see if the selection probability of a given category of perceived noise is biased upward. The estimation confirms that the dwellings exposed to "moderate", "important" and "very important" perceived external noise have a higher probability to be included in our sample.

4 Miedema and Oudshoorn (2001) present a more accurate relationship of third-order polynomial order. For calculation reasons, we refer to their "simple" model. From Eq. (2), that 42 is subtracted from $L_{d n}$ since they observed that the \%HA fell to zero at $L_{d n}$ equal to $42 \mathrm{~dB}(\mathrm{~A})$.

5 Counting no individuals in category 2 as highly annoyed does not change our results.
} 


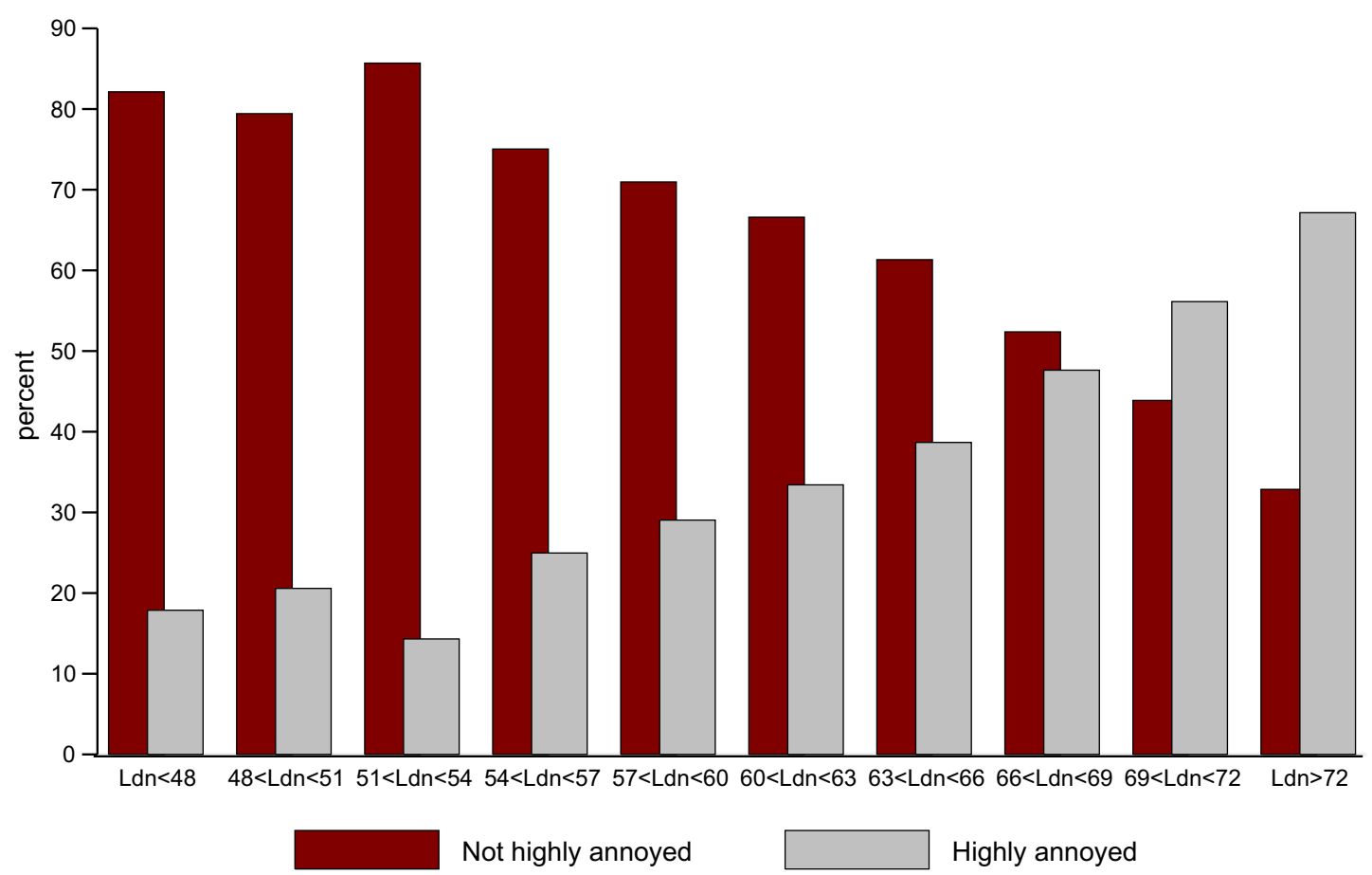

Data sources: Statistical Information on Rent Structure 2003, Geneva Cantonal Office for Protection against Noise.

Fig. 1. Distribution of perceived exposure to noise, by $\mathrm{dB}(\mathrm{A})$ level.

Finally, we use the reverse of Eq. (2) to transform the calculated \%HA into a subjective $L_{d n}$ noise measure expressed in $\mathrm{dB}(\mathrm{A})$; unlike aircraft noise, the relationship between \%HA and exposure to road traffic noise seems to be stable over time (Babisch et al., 2007). The relation between the measured $L_{d n}$ and the subjective $L_{d n}$ is illustrated in Fig. 2. A clear relationship between the variables is seen, even though all subjective noise values lie above the diagonal. This is not surprising because measured $L_{d n}$ refers only to road noise whereas the subjective $L_{d n}$ is based on a survey question about all "external noise".

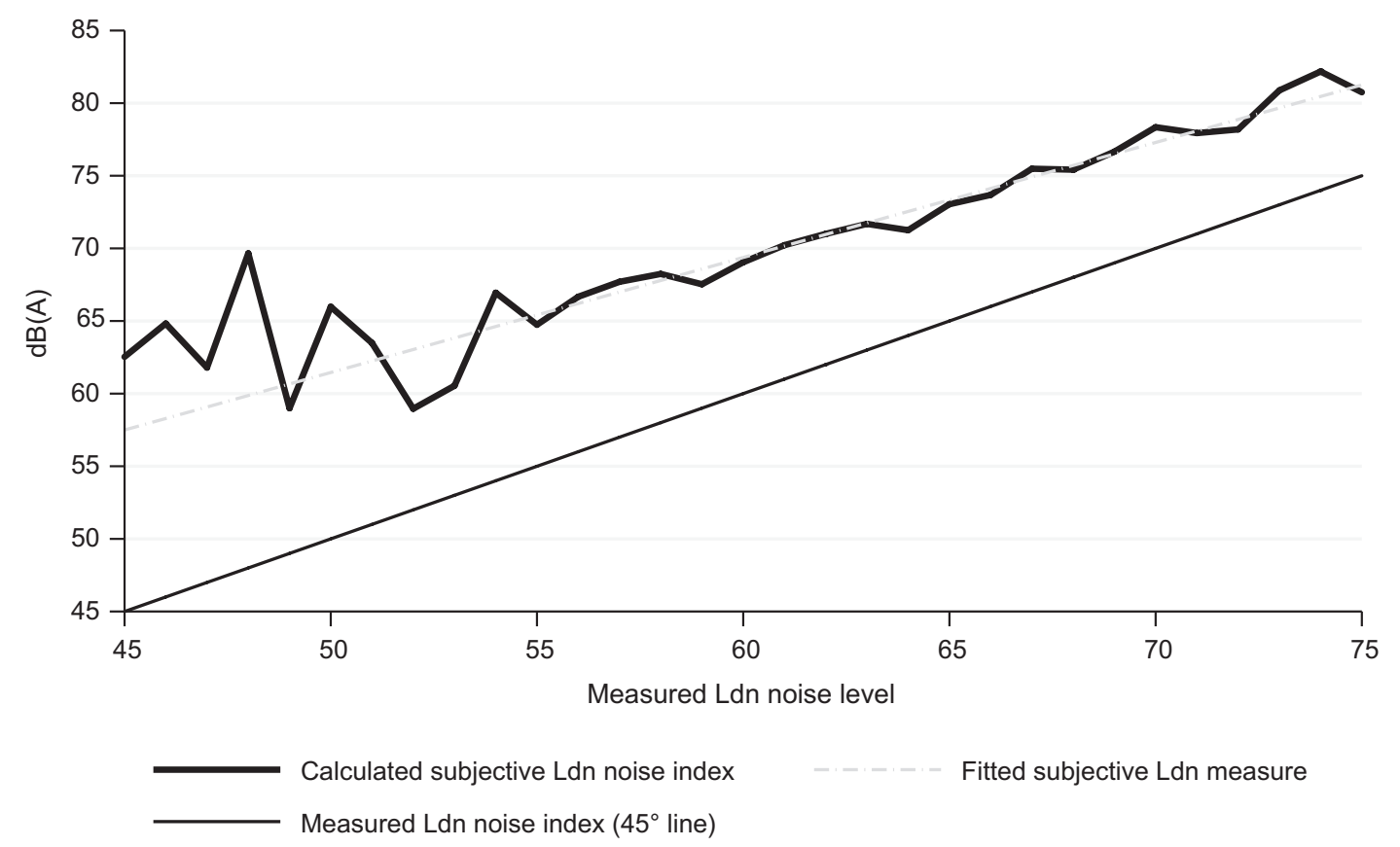

Data sources: Statistical Information on Rent Structure 2003, Geneva Cantonal Office for Protection against Noise.

Fig. 2. Measured and subjective $L_{d n}$ noise in $\mathrm{dB}(\mathrm{A})$. 
Fig. 2 offers two insights. First, for low values of measured $L_{d n}$ there is a lot of variability in the perception of noise. This result is in line other findings that the data is often highly unreliable for low noise levels. We, therefore, only use observations for which there is a "stable" relationship, i.e. those for which measured $L_{d n}$ exceeds $55 \mathrm{~dB}(\mathrm{~A})$. Secondly, subjective $L_{d n}$ increases less than proportionally with measured $L_{d n}$ above $55 \mathrm{~dB}(\mathrm{~A})$. This may be due to an under-estimation of the low frequency components of noise in the A-weighting measure (St. Pierre and Maguire, 2004) or to over- and under-estimation of low and high probability events in risk evaluation (Tversky and Kahneman, 1992). This systematic bias implies that the marginal compensation for any incremental increase in perceived risk is lower than the compensation individuals would ask based on measured risk (Viscusi, 1993). In the noise context, this explanation would mean that the implicit price of an additional decibel of perceived noise is lower than that of measured noise, at any given noise level.

\section{Sample and descriptive statistics}

Once we are able to compare perceived and measured noise, the next step is to test whether the different noise measures have an impact on the estimation of a HPM, in particular the implicit value of quietness.

To obtain the relevant variables, including perceived and measured noise at the apartment level, we had to gather data from different sources. Our base dataset is the 2003 Statistical information Survey on Rent Structure from the Swiss Federal Statistical Office. This dataset is based on a survey of 320,000 randomly selected Swiss households, with detailed questions on rents, the structure of the dwelling and its direct neighbourhood. Originally, the sample of the statistical survey for the canton of Geneva included 18,943 observations for the whole canton, both from owners and renters, of which 7578 are complete (i.e. without missing values) on all structural variables we are interested in. Excluding home-owners, in order to concentrate on the rental market (over $80 \%$ of Geneva households rent their home), and recipients of special rent discounts (caretakers, relatives of the property owner, and tenants of cooperative or subsidized housing) leaves us with 4421 observations. There are no single-family houses left in the sample. The survey responses allow constructing a categorical variable measuring perceived external noise.

This database is then merged with information on road traffic noise obtained from the Geneva Cantonal Office for Protection against Noise. Given that noise is not measured for all streets of the canton, we lose another third of our sample. Moreover, we exclude those observations for which the $L_{d n}$ noise exposure lies above $75 \mathrm{~dB}(\mathrm{~A})$ because measured noise variables at those levels are unreliable (Miedema and Oudshoorn, 2001). In the same vein, we exclude observations for which the measured noise level is less than $55 \mathrm{~dB}(\mathrm{~A})$ during the day or $45 \mathrm{~dB}(\mathrm{~A})$ during the night. These thresholds also correspond to the planning regulations for housing areas in Swiss law (Swiss Noise Abatement Ordinance, 1986). ${ }^{6}$ Finally, 72 outliers are dropped using the Welsch distance criteria. Inspection of these outliers reveals that their rent is over 10 times the mean rent in the sample, which hints at miscoding. The final dataset contains 2840 observations. The sample is representative of the Statistical Information Survey on Rent Structure in terms of rents, number of rooms and construction periods.

The third source of information is a GIS database, the Information System of the Geneva Territory (SITG). From this database, we compute for all dwellings their distance to the nearest park and the nearest primary school, as well as the density of historical buildings in its neighbourhood defined as a statistical sub-sector. ${ }^{7}$

Table 2 reports the descriptive statistics of our sample. The mean monthly rent in 2003 is $\mathrm{CHF}_{1243^{8}}$ for the whole sample, but its variance is very large. Most of the buildings included in our sample were built before 1971 , yet only $16 \%$ are totally renovated. Almost $38 \%$ of the buildings belong to an insurance company or a pension fund, about $23 \%$ to a private person, and $3 \%$ to a public entity (municipal, cantonal or federal government). The dwellings count 3.1 rooms on average, whose mean surface is $27 \mathrm{~m}^{2}$. The mean duration of residence in the same dwelling is quite long, about 15 years, but the range is also very large, from 0 to 86 years. Note that long tenures are not concentrated in specific districts. This variable has a role to play on the monthly rent, because landlords generally raise rents at changes in tenancy (Thalmann, 1987).

The accessibility variables, constructed using the GIS data, show that $70 \%$ of the dwellings are located in the city centre with a mean distance to the nearest park of $163 \mathrm{~m}$ and $213 \mathrm{~m}$ to the nearest primary school. This illustrates that the Canton of Geneva is small and dense; it has about 440,000 inhabitants on $282 \mathrm{~km}^{2}$ with spatially concentrated infrastructure. As to neighbourhood and aesthetic variables, the mean density of historical buildings per neighbourhood is $0.7 \%$, with a high concentration in the old town, and few historical buildings dispersed around the canton. Seven percent of the dwellings enjoy a view on the lake of Geneva, while $46 \%$ have a view of the mountains. ${ }^{9}$ Unlike most HPM for the US housing market, we do not account for the quality of public goods of the neighbourhoods (such as quality of policing), because appropriate data are not available and there is not much variability across neighbourhoods.

\footnotetext{
${ }^{6}$ Authors have processed data for low noise levels in different, often ad hoc, ways. For example, Bjørner (2004) limits the sample to households in Copenhagen exposed to noise levels between 55 and $75 \mathrm{~dB}(\mathrm{~A})$. Banfi et al. (2008) use road traffic noise levels in Zurich only for streets where noise limit values during the night have been exceeded $50 \mathrm{~dB}(\mathrm{~A})$ and assign an exposure value of $50 \mathrm{~dB}(\mathrm{~A})$ to all the buildings for which the measured noise level was not calculated.

7 The statistical sub-sector is an intermediate territorial entity between the plot and the municipality. The density is calculated as the number of historical buildings divided by the surface of the neighbourhood, times one hundred.

8 In June 2003, CHF $1=\$ 0.76$ or $€ 0.65$.

9 These are subjective appreciations of the view. Based on GIS data, Baranzini and Schaerer (2007) develop variables able to characterise the view more precisely.
} 
Table 2

Descriptive statistics $(n=2840)$.

\begin{tabular}{|c|c|c|c|c|}
\hline Variable & Mean & Std. Dev. & Min & Max \\
\hline Mean net monthly rent & 1243 & 572 & 177 & 8258 \\
\hline \multicolumn{5}{|l|}{ Structural variables } \\
\hline Built between 1971 and 1980 & 0.138 & 0.345 & 0 & 1 \\
\hline Built between 1981 and 1990 & 0.061 & 0.240 & 0 & 1 \\
\hline Built between 1991 and 2003 & 0.055 & 0.227 & 0 & 1 \\
\hline Totally renovated building & 0.158 & 0.365 & 0 & 1 \\
\hline Elevator in the building & 0.775 & 0.418 & 0 & 1 \\
\hline Privately owned building & 0.234 & 0.423 & 0 & 1 \\
\hline Publicly owned building & 0.033 & 0.178 & 0 & 1 \\
\hline Owner is an insurance company or a pension fund & 0.382 & 0.486 & 0 & 1 \\
\hline Ownership is unknown & 0.352 & 0.478 & 0 & 1 \\
\hline Number of floors in the building & 7.008 & 2.643 & 1 & 23 \\
\hline Number of rooms & 3.057 & 1.158 & 1 & 6 \\
\hline Surface per room $\left[\mathrm{m}^{2}\right]$ & 26.677 & 7.025 & 7 & 60 \\
\hline Floor level & 3.557 & 2.518 & 0 & 19 \\
\hline Dwelling with terrace/garden & 0.102 & 0.303 & 0 & 1 \\
\hline Attic & 0.066 & 0.248 & 0 & 1 \\
\hline Balcony & 0.636 & 0.481 & 0 & 1 \\
\hline Separated toilet & 0.235 & 0.424 & 0 & 1 \\
\hline \multicolumn{5}{|l|}{ Accessibility variables } \\
\hline Located in city centre [dummy] & 0.705 & 0.456 & 0 & 1 \\
\hline Distance to nearest park $[\mathrm{m}]$ & 162.922 & 118.434 & 0 & 1238 \\
\hline Distance to nearest primary school [m] & 212.503 & 107.539 & 0 & 1226 \\
\hline \multicolumn{5}{|l|}{ Neighbourhood/aesthetic variables } \\
\hline Density of historical buildings & 0.742 & 1.989 & 0 & 21 \\
\hline View on the lake [dummy] & 0.073 & 0.261 & 0 & 1 \\
\hline View on the mountains [dummy] & 0.464 & 0.499 & 0 & 1 \\
\hline \multicolumn{5}{|l|}{ Noise variables } \\
\hline$L r_{D}[\mathrm{~dB}(\mathrm{~A})]$ & 65.421 & 4.659 & 50 & 74 \\
\hline$L_{d n}[\mathrm{~dB}(\mathrm{~A})]$ & 67.027 & 5.029 & 53 & 75 \\
\hline
\end{tabular}

Source: From the Statistical Information on Rent Structure 2003, from the SITG, and from Geneva Cantonal Office for Protection against Noise.

\section{Application and results}

Here we analyse the performance of perceived vs. measured noise within a HPM by using two different procedures. First, we test whether the coefficients depend of the choice of the noise measure, by estimating, as in Poor et al. (2001), identical equations except for the noise variable. We test whether the use of the subjective variable adds any explanatory power to the estimation, especially because it incorporates extra information about external noise. In this context, we apply both an instrumental approach and a classic interaction approach using dummies.

Since theory does not dictate any functional form for the hedonic equation, it has to be determined empirically. Linear, semi-logarithmic, log-linear, as well as linear Box-Cox transformations are commonly used. After linear and logarithmic functional forms are both rejected by the Davidson-MacKinnon PE-test, we test Box-Cox transformations of the dependent and independent variables jointly and alternatively. The semi-logarithmic functional form appears to be the most appropriate. We introduce the square of the duration of residence to account for the non-linearity of its impact on rent. Finally, we estimate the hedonic equation by ordinary least squares (OLS):

$$
\ln Y_{i}=\alpha+\sum_{m=1}^{M} \beta_{i m} z_{i m}+\lambda \text { noise }_{i}+u_{i}
$$

where $\ln Y_{i}$ is the natural logarithm of the 2003 monthly rent of dwelling $i$; $z_{\text {im }}$ corresponds to characteristic $m$ $(m=1, \ldots, M)$ of dwelling $i$; noise $e_{i}$ stands for noise measure at building sheltering $i$; and $u_{i}$ is an error term reflecting all the unobservable.

To check for spatial correlation, we performed the Moran's I and the Lagrange tests on the OLS residuals (Anselin, 2003). Both reject the null hypothesis of the absence of spatial correlation. Therefore, we draw a robust semivariogram to determine the sill, i.e. the distance at which the spatial correlations between observations fall to zero. Based on this information, we build a spatial (row standardized) weight matrix $W$, in which all buildings that are located within $100 \mathrm{~m}$ from one another 
Table 3

Results, models day, day-night and Subj-Ldn.

\begin{tabular}{|c|c|c|c|}
\hline $\begin{array}{l}\text { Models } \\
\text { Dependent variable: } \ln (\text { net monthly rent) } \\
\text { Variable }\end{array}$ & $\begin{array}{l}\text { Day } \\
(n=2840) \\
\text { Coeff. }\end{array}$ & $\begin{array}{l}\text { Day-night } \\
(n=2840) \\
\text { Coeff. }\end{array}$ & $\begin{array}{l}\text { Subj-Ldn } \\
(n=2840) \\
\text { Coeff. }\end{array}$ \\
\hline \multicolumn{4}{|l|}{ Structural variables } \\
\hline Built between 1961 and 1970 & 0.023 & 0.023 & 0.023 \\
\hline Built between 1971 and 1980 & $0.072^{* * *}$ & $0.072^{* * *}$ & $0.072^{* * *}$ \\
\hline Built between 1981 and 1990 & $0.172^{* * *}$ & $0.172^{* * *}$ & $0.172^{* * *}$ \\
\hline Built between 1991 and 2003 & $0.099^{* * *}$ & $0.099^{* * *}$ & $0.099^{* * *}$ \\
\hline Totally renovated building & $0.038^{* * *}$ & $0.038^{* * *}$ & $0.038^{* * *}$ \\
\hline Elevator in the building & $0.048^{* * *}$ & $0.048^{* * *}$ & $0.048^{* * *}$ \\
\hline Privately owned building & $0.051^{* *}$ & $0.051^{* *}$ & $0.051^{* * *}$ \\
\hline Publicly owned building & $-0.153^{* * *}$ & $-0.153^{* * *}$ & $-0.153^{* * *}$ \\
\hline Number of floors in the building & $-0.007^{* * *}$ & $-0.007^{* * *}$ & $-0.007^{* * *}$ \\
\hline Number of rooms & $0.253^{* * *}$ & $0.253^{* * *}$ & $0.253^{* * *}$ \\
\hline Surface per room $\left[\mathrm{m}^{2}\right]$ & $0.011^{* * *}$ & $0.011^{* * *}$ & $0.011^{* * *}$ \\
\hline Floor level & $0.004^{*}$ & $0.004^{*}$ & $0.004^{*}$ \\
\hline Dwelling with terrace/garden & $0.081^{* * *}$ & $0.081^{* * *}$ & $0.081^{* * *}$ \\
\hline Attic & $0.096^{* * *}$ & $0.095^{* * *}$ & $0.095^{* * *}$ \\
\hline Balcony & $0.044^{* * *}$ & $0.044^{* * *}$ & $0.043^{* * *}$ \\
\hline Separated toilet & $0.084^{* * *}$ & $0.084^{* * *}$ & $0.084^{* * *}$ \\
\hline Duration of residence [years] & $-0.017^{* * *}$ & $-0.017^{* * *}$ & $-0.017^{* * *}$ \\
\hline Square of the duration of residence $(\times 100)$ & $0.014^{* * *}$ & $0.014^{* * *}$ & $0.014^{* * *}$ \\
\hline \multicolumn{4}{|l|}{ Accessibility variables } \\
\hline Located in city centre [dummy] & $0.082^{* * *}$ & $0.082^{* * *}$ & 0.082 \\
\hline Distance to nearest park [km] & $-0.072^{*}$ & $-0.072^{*}$ & $-0.072^{*}$ \\
\hline Distance to nearest primary school $[\mathrm{km}]$ & $0.146^{* * *}$ & $0.147^{* * *}$ & $0.146^{* * *}$ \\
\hline \multicolumn{4}{|l|}{ Neighbourhood/aesthetic variables } \\
\hline Density of historical buildings $(\times 100)$ & $0.599^{* * *}$ & $0.589^{* *}$ & $0.593^{* *}$ \\
\hline View on the lake [dummy] & $0.089^{* * * *}$ & $0.089^{* * *}$ & $0.090^{* * *}$ \\
\hline View on the mountains [dummy] & $0.027^{* *}$ & $0.027^{* *}$ & $0.027^{* *}$ \\
\hline \multicolumn{4}{|l|}{ Noise variables } \\
\hline$L r_{D}[\mathrm{~dB}(\mathrm{~A})](\times 100)$ & $-0.226^{* *}$ & & \\
\hline$L_{d n}[\mathrm{~dB}(\mathrm{~A})](\times 100)$ & & $-0.197^{*}$ & \\
\hline Subjective $L_{d n}[\mathrm{~dB}(\mathrm{~A})](\times 100)$ & & & $-0.242^{*}$ \\
\hline$R$-squared & 0.6588 & 0.6587 & 0.6588 \\
\hline F-stat. & 228.97 & 229.04 & 229.25 \\
\hline Mean VIF & 1.78 & 1.78 & 1.78 \\
\hline
\end{tabular}

Note: The reference for the period of construction is before 1961, while the reference for the owner type is composed of insurance, pension funds or unknown owners. Data sources: Statistical Information on Rent Structure 2003, SITG, and Geneva Cantonal Office for Protection against Noise.

* Significant at the 0.10 level.

** Significant at the 0.05 level.

*** Significant at the 0.01 level.

are considered as neighbours. ${ }^{10}$ Finally, we re-estimate Eq. (3) using the spatial generalized method of moments (GMM) estimator (Kelejian and Prucha, 1999) and the maximum likelihood (ML) estimator for simultaneous autoregressive error models. The results with the GMM and ML estimators are statistically the same as those with OLS.

To test whether there are different coefficients for different noise measures, we estimate, a "Day" model, estimated with the daytime road traffic noise measure $\left(L r_{D}\right)$, which is the reference measure in Swiss legislation; a "Day-Night" model estimated using the day-night noise index $\left(L_{d n}\right)$; and a "Subj-Ldn" model with a subjective $L_{d n}$ noise measure. The estimations of the parameters from these models are seen in Table 3.

The analysis of simple correlation matrices indicates that there are no significant dependencies between the variables, and the variance inflation factor (VIF) test confirms that there is no problem of multicolinearity. We use White's heteroskedastic-consistent estimator of variance because the Breusch-Pagan test rejects the null hypothesis of constant variance. The various models produce similar results. They explain 66\% of the variance of rents in the Canton of Geneva. Almost all variables are statistically significant with expected signs. The F-statistic rejects the null hypothesis that all parameters are jointly equal to zero at the $1 \%$ level. Moreover, the coefficients are very stable across the models and traditional $t$-tests show that the equality of the coefficients between them, including those of noise parameters, cannot be rejected.

\footnotetext{
10 This is also the distance that maximizes the Moran's I statistics, a criterion used by Baumont (2004) to build the weight matrix.
} 
Table 4

Results, models Subj-Obj and interaction.

\begin{tabular}{|c|c|c|}
\hline $\begin{array}{l}\text { Models } \\
\text { Dependent variable: } \ln (\text { net monthly rent) } \\
\text { Variable }\end{array}$ & $\begin{array}{l}\text { Subj-Obj } \\
(n=2840) \\
\text { Coeff. }\end{array}$ & $\begin{array}{l}\text { Interaction } \\
(n=2945) \\
\text { Coeff. }\end{array}$ \\
\hline $\begin{array}{l}\text { Structural, accessibility and neighbourhood variables } \\
(\ldots)\end{array}$ & $(\ldots)$ & $(\ldots)$ \\
\hline $\begin{array}{l}\text { Noise variables } \\
L r_{D}[\mathrm{~dB}(\mathrm{~A})](\times 100) \\
\text { Error of the regression subjective-objective }(\times 100) \\
\text { Dummy (no noise) } \times L r_{D} \mathrm{~dB}(\mathrm{~A})(\times 100) \\
\text { Dummy (slightly no noise } \times L r_{D}[\mathrm{~dB}(\mathrm{~A})](\times 100) \\
\text { Dummy (moderate noise) } \times L r_{D}[\mathrm{~dB}(\mathrm{~A})](\times 100) \\
\text { Dummy (important noise) } \times L r_{D}[\mathrm{~dB}(\mathrm{~A})](\times 100) \\
\text { Dummy (very important noise }) \times L r_{D}[\mathrm{~dB}(\mathrm{~A})](\times 100)\end{array}$ & $\begin{array}{c}-0.233^{* *} \\
0.092\end{array}$ & $\begin{array}{l}-0.143 \\
-0.206^{* *} \\
-0.190^{*} \\
-0.201^{* *} \\
-0.208^{* *}\end{array}$ \\
\hline $\begin{array}{l}R \text {-squared } \\
F \text {-stat. } \\
\text { Mean VIF }\end{array}$ & $\begin{array}{l}0.6588 \\
218.34 \\
1.76\end{array}$ & $\begin{array}{l}0.6596 \\
202.20 \\
6.10\end{array}$ \\
\hline
\end{tabular}

Data sources: Statistical Information on Rent Structure 2003, SITG, and Geneva Cantonal Office for Protection against Noise.

* Significant at the 0.10 level.

** Significant at the 0.05 level.

*** Significant at the 0.01 level.

\subsection{Interpreting the estimates}

Given the semi-logarithmic functional form of the estimated hedonic Eq. (3), the coefficients of the continuous variables represent semi-elasticities, i.e. the percentage change in the rent for a given unit change in the independent variables, all the other characteristics remaining the same. For instance, the results show that, all else equal, an additional $\mathrm{m}^{2}$ per room has a positive impact on rents of $1.1 \%$ on average. The duration of residence, specified with a quadratic effect, has a negative impact on rent, which amounts to $22 \%$ for the mean duration of residence of 15 years.

The dummy variables are not directly interpretable but transformed using the formula $\left(e^{\beta}-1\right)$ to obtain the percent change in the dependent variable (Halvorsen and Palmquist, 1980). Therefore, for instance, a dwelling with a terrace or garden is rented $8.4 \%$ higher, while the rent premium is on average $8.5 \%$ for a dwelling located in the city centre. Professionals in the Swiss urban rental markets consider that the existence of a second toilet in the dwelling or a separated one is an indication of a higher standard of the dwelling. The results confirm that rents of dwellings with a separated toilet are, ceteris paribus, 8.7\% higher. Newer buildings generally command higher rents, although there is a small discount in buildings built since 2000 reflecting the supply side - construction and land prices declined after the boom of the 1980s.

Regarding the impact of noise on rents, an increase by $1 \mathrm{~dB}(\mathrm{~A})$ reduces the rent by $0.197-0.242 \%$, depending on the noise measure used. ${ }^{11}$ This is comparable to the findings from other hedonic studies of the Swiss and Geneva markets that use measured noise data (Schaerer et al., 2007).

The coefficients of the model with the measured daytime road traffic noise level (models "Day" and "Day-Night") are slightly lower than the coefficients of the model with our calculated subjective $L_{d n}$ noise measure (model "Subj-Ldn"). However, equality tests show that the coefficients are not statistically different. Consequently, unlike the under-estimation of high risk (Viscusi, 1993) there is no evidence here of a significant difference between the implicit prices of noise obtained with perceived and objective data.

\subsection{Testing for the source of noise}

Although the perceived noise variable refers to all sources of external noise, we find that its coefficient is not statistically different to that of the two measured road traffic noise variables. This suggests that the latter are good approximations for all external noise in the Canton of Geneva. To test this assumption more precisely, we follow Chattopadhyay et al. (2004) in using an instrumental approach that allows disentangling of the external noise arising from measured road traffic noise from the subjective $L_{d n}$. Instrumenting the subjective $L_{d n}$ measure with the daytime road noise yields residuals that can be seen as the pure effect of "other external noise", i.e. external noise arising from sources other than road traffic. Next, we plug the residuals of this subjective-objective regression into our hedonic equation with the measured daytime road traffic noise. The results of this estimation are reported in the first column of Table 4 (model "Subj-Obj"). Since the coefficients associated with all the structural, accessibility and neighbourhood variables are the same as in Table 3 . Table 4 shows only the coeffi-

\footnotetext{
11 Following Jacobs Consultancy (2008), we estimate a hedonic model using the percentage of people highly annoyed by external noise as the noise variable. The results show that \%HA has a significant impact on rent, each per cent of people highly annoyed leading to a decrease of $0.11 \%$.
} 
cients of the noise variables. The statistically significant coefficient of the measured noise variable is equal to -0.23 , while the coefficient of the residuals from the subjective-objective regression is not statistically significant. This indicates that there is no additional explanative power of the subjective $L_{d n}$ variable over the measured daytime road traffic noise and that "other external noise" does not have any specific influence on rents. If this finding is correct, the inclusion of the original perceived external noise data would not improve the estimations either.

To test more specifically for this assumption, we consider the interaction effects between the daytime road traffic noise level in $\mathrm{dB}(\mathrm{A})$ and the original perceived external noise. Therefore, for each category of the perceived external noise we create separate binary dummy variables and interact them with the measured daytime noise $\left(\operatorname{Lr}_{D}\right)$. Then we estimate a hedonic model in which we introduce the new interaction terms. Given that a category of perceived external noise is "no noise", in this estimation we do not constrain the sample to the dwellings that are exposed to road traffic noise levels of at least to $55 \mathrm{~dB}(\mathrm{~A})$ during the day or $45 \mathrm{~dB}(\mathrm{~A})$ during the night. The estimation results for this specification of the noise variables are reported in column 2 of Table 4 (model "Interaction"). The coefficients of all the other variables are the same as in Table 3. It appears that the coefficients of the interaction terms are all significant, except the one related to "no noise". Analysing the value of the interaction terms coefficients, Wald tests confirm that they are jointly equal $(p$-value $=0.61)$ and that all of the interaction coefficients are individually statistically equal, at the $1 \%$ level, to the coefficient of the daytime noise measure in model "Day" $\left(L r_{D}=-0.226\right)$ reported in Table 3. These results suggest that the use of perceived external noise measures does not improve the estimation outcome and that measured noise approximates them efficiently when the road traffic noise is perceived as not null. This result also validates our previous choice to exclude from the sample the observations with low noise levels before estimating the models reported in Table 3.

\section{Conclusions}

This paper compared the use of measured and perceived noise in a hedonic housing price model. It is recognised that for property prices to be affected by environmental characteristics, the latter have to be perceived by the residents. However, there has been limited discussion on the possible biases introduced in the common practice of using measured noise variables. We use data containing both objective and perceived noise and make the two noise measures directly comparable. We showed a clear relationship between the measured road traffic noise and our categorical variable of perceived external noise transformed into $\mathrm{dB}(\mathrm{A})$, even though there is great variability in the perception of noise when the measured noise level is relatively small.

We analysed the performance of perceived vs. measured noise data in a HPM by fitting three equations with different noise measures; daytime road traffic noise, day-night road traffic noise index, and subjective $L_{d n}$ in decibels calculated from perceived external noise data. We found that the coefficients, including those on noise, are statistically equal across models, although the coefficient of our subjective $L_{d n}$ in $\mathrm{dB}(\mathrm{A})$ is not statistically significant when "no noise" is perceived. Nevertheless, from the tests performed, we can confirm convergence in the perceived and measured noise variables. We also found that using the subjective measure does not improve the estimation. From all this, we can conclude that for moderate to high noise levels, the measured noise safely approximates the individual perception of noise. Thus HPM using measured noise data provide results just as good as those that use subjective data.

\section{Acknowledgements}

We are grateful for financial support from the Swiss National Science Foundation, National Research Programme NRP 54 "Sustainable Development of the Built Environment". We thank the Swiss Federal Statistical Office for providing the data; Mario Levental of the Geneva Cantonal Office for Protection against Noise for the measured noise data; the Geneva Cantonal Office for Information Systems and Geomatics for the GIS data; Alain Dubois for technical support with the GIS data; and José Ramirez, Rainer Guski, Henk Miedema, Cristian Ugarte Romero, Sylvain Weber, two anonymous referees for their comments on a previous version of the paper. The usual disclaimer applies.

\section{References}

Anselin, L., 2003. Spatial externalities, spatial multipliers and spatial econometrics. International Regional Science Review 26 (2), $153-166$.

Babisch, W., Houthuijs, D., Pershagen, G., Cadum, E., Velonakis, M., Katsouyanni, K., Jarup, L., 2007. Associations between road traffic noise, aircraft noise and noise annoyance. Preliminary results of the HYENA study. In: 19th International Congress on Acoustics, Madrid.

Banfi, S., Filippini, M., Horehajava, A., 2008. Valuation of environmental goods in profit and non-profit housing sectors: evidence from the rental market in the City of Zurich. Swiss Journal of Economics and Statistics 144, 631-654.

Baranzini, A., Schaerer, C., 2007. A Sight for Sore Eyes: Assessing the Value of View and Landscape Use on the Housing Market. Cahier de Recherche HES-SO/ HEG-GE/C-07/1/1-07. Haute École de Gestion, Geneva, Switzerland. <http://ssrn.com/abstract=981189>.

Baranzini, A., Schaerer, C., Ramirez, J.V., Thalmann, P. (Eds.), 2008. Hedonic Methods in Housing markets. Pricing Environmental Amenities and Segregation. Springer, New York.

Bateman, I.A., Day, B.H., Lake, I.R., Lovett, A.A., 2001. The Effect of Road Traffic on Residential Property Values: A Literature Review and Hedonic Price Study. Scottish Executive Transport Research Series. The Stationery Office, Edinburgh.

Baumont, C., 2004. Spatial Effects in Housing Price Models: Do Housing Prices Capitalize Urban Development Policies in the Agglomeration of Dijon? Working Paper 2004-04. Laboratoire d'Economie et de Gestion, Dijon.

Bjørner, T.B., 2004. Combining socio-acoustic and contingent valuation surveys to value noise reduction. Transportation Research Part D 9, 341-356. 
Chattopadhyay, S., Braden, J.B., Patunru, A., 2004. Perceived environmental value in revealed data: evidence from housing market. In: Allied Social Sciences Association Meetings, San Diego.

Halvorsen, R., Palmquist, R.B., 1980. The interpretation of dummy variables in semilogarithmic equations. American Economic Review 70, 474-475.

Jacobs Consultancy, 2008. The impact of aircraft noise on residential property values in the Bob Hope airport environs. Supplemental technical report number 2. Prepared for Burbank-Glendale-Pasadena Airport Authority, Burbank California, in association with J.P. Nelson.

Kelejian, H.H., Prucha, I.R., 1999. A generalized moments estimator for the autoregressive parameter in a spatial model. International Economic Review 40, 509-533.

Miedema, H.M.E., Oudshoorn, C.G.M., 2001. Annoyance from transportation noise: relationships with exposure metrics DNL and DENL and their confidence interval. Environmental Health Perspectives 109, 409-416.

Miedema, H.M.E., Vos, H., 1998. Exposure-response relationships for transportation noise. Journal of the Acoustical Society of America $104,3432-3445$.

Navrud, S., 2002. The State-of-the-Art on Economic Valuation of Noise. Final Report to European Commission. Directorate General Environment Department of Economics and Social Sciences, Agricultural University of Norway.

Nelson, J.P., 2008. Hedonic property studies of transportation noise: aircraft and road traffic. In: Baranzini, A., Ramirez, J., Schaerer, C., Thalmann, P. (Eds.), Hedonic Methods in Housing Markets. Pricing Environmental Amenities and Segregation. Springer, New York.

Palmquist, R.B., 2005. Property value models. In: Mäler, K.G., Vincent, J.R. (Eds.), Handbook of Environmental Economic, vol. 2. Elsevier, Amsterdam.

Pommerehne, W.W., 1987. L'évaluation des gains et des pertes d'aménités: Le cas du bruit provenant du trafic. In: Burgat, P., Jeanrenaud, C. (Eds.), Services Publics Locaux. Economica, Paris.

Poor, J.P., Boyle, K.J., Taylor, L.O., Bouchard, R., 2001. Scientific versus subjective measures of water clarity in hedonic property value models. Land Economics $77,482-493$

Schaerer, C., Baranzini, A., Ramirez, J.V., Thalmann, P., 2007. Using the hedonic approach to value landscape uses in an urban area: an application to Geneva and Zurich. Economie Publique - Public Economics 20 (1), 147-167.

Schultz, T.J., 1978. Synthesis of social surveys on noise annoyance. The Journal of the Acoustical Society of America 64, 377-405.

Soguel, N., 1994. Évaluation monétaire des atteintes à l'environnement: une étude hédoniste et contingente sur l'impact des transports. EDEC, Neuchâtel.

St. Pierre, R.L., Maguire, D.J., 2004. The impact of A-weighting sound pressure level measurements during evaluation of noise exposure. Paper presented at the Conference NOISE-CON, 12-14 June, Baltimore, Maryland, United States.

Swiss Noise Abatement Ordinance, 1986. SR 814.41.AS 1987 338. Bern, Switzerland.

Thalmann, P., 1987. Explication empirique des loyers lausannois. Swiss Journal of Economics and Statistics 123 (1), 47-69.

Tversky, A., Kahneman, D., 1992. Advances in prospect theory: cumulative representation of uncertainty. Journal of Risk and Uncertainty 5 (4), $297-323$.

Viscusi, K.W., 1993. The value of risk to life and health. Journal of Economic Literature 31, 1912-1946. 